\title{
ORIGINAL ARTICLE \\ Short-term genetic consequences of habitat loss and fragmentation for the neotropical palm Oenocarpus bataua
}

\author{
L Browne $^{1}$, K Ottewell ${ }^{1,2}$ and J Karubian ${ }^{1}$
}

Habitat loss and fragmentation may impact animal-mediated dispersal of seed and pollen, and a key question is how the genetic attributes of plant populations respond to these changes. Theory predicts that genetic diversity may be less sensitive to such disruptions in the short term, whereas inbreeding and genetic structure may respond more strongly. However, results from studies to date vary in relation to species, context and the parameter being assessed, triggering calls for more empirical studies, especially from the tropics, where plant-animal dispersal mutualisms are both disproportionately common and at risk. We compared the genetic characteristics of adults and recruits in a long-lived palm Oenocarpus bataua in a recently fragmented landscape ( $<2$ generations) in northwest Ecuador using a suite of 10 polymorphic microsatellite markers. We sampled individuals from six forest fragments and one nearby continuous forest. Our goal was to assess short-term consequences of fragmentation, with a focus on how well empirical data from this system follow theoretical expectations. Mostly congruent with predictions, we found stronger genetic differentiation and fine-scale spatial genetic structure among recruits in fragments compared with recruits in continuous forest, but we did not record differences in genetic diversity or inbreeding, nor did we record any differences between adults in fragments and adults in continuous forest. Our findings suggest that genetic characteristics of populations vary in their sensitivity to change in response to habitat loss and fragmentation, and that fine-scale spatial genetic structure may be a particularly useful indicator of genetic change in recently fragmented landscapes.

Heredity (2015) 115, 389-395; doi:10.1038/hdy.2015.35; published online 29 April 2015

\section{INTRODUCTION}

Habitat loss and fragmentation can profoundly impact the genetic characteristics of species by altering population sizes and patterns of gene flow. Many plant species rely on animals for dispersal (Herrera, 2002; Ollerton et al., 2011), and disruptions to these dispersal mutualisms may alter the movement of pollen, seeds or both. For example, dispersal limitation associated with habitat loss and fragmentation may drive a decline in genetic diversity, an increase in inbreeding and an increase in genetic differentiation among isolated populations (Young et al., 1996). In what has been termed the 'paradox of forest fragmentation genetics' (Kramer et al., 2008), many long-lived plant species fail to exhibit a decline in genetic diversity following habitat loss and fragmentation, potentially indicating that gene flow may not be limited for some species (Dick, 2001; White et al., 2002), or that too few generations have passed for genetic erosion to be detectable (Lowe et al., 2005). In contrast, the mating system and fine-scale spatial genetic structure (SGS) of plant populations may respond immediately or within a single generation (Lowe et al., 2005; Wang et al., 2011). It is becoming increasingly clear that a suite of changes may be expected post fragmentation and that different genetic characteristics vary in their degree of sensitivity to change (Varvio et al., 1986; Lowe et al., 2005; Kramer et al., 2008). For this reason, there is a need for more empirical data on how different genetic attributes respond to habitat loss and fragmentation to better understand the contemporary and future status of fragmented populations.
For plant species that experience limited gene flow and reduced population sizes following habitat loss and fragmentation, immediate genetic consequences may include the loss of rare alleles, increased inbreeding and increased fine-scale SGS (Young et al., 1996; Lowe et al., 2005; Wang et al., 2011). These consequences arise from changes in patterns of gene dispersal and the demographic and spatial structure of recruits. The loss of rare alleles and a decline in allelic richness are likely to occur from the immediate loss of individuals following habitat destruction (Young et al., 1996; Lowe et al., 2005). Reduced pollen diversity and increased inbreeding through selfing or mating with close relatives may result from changes in the behavior and distribution of pollinators in fragmented landscapes, contributing to short-term alteration of the realized mating systems of plants (Breed et al., 2012). The fine-scale SGS of recruits may also respond in the short-term (Wang et al., 2011), particularly, if long-distance seeddispersal agents are extirpated and recruits are subsequently clumped with related individuals. In contrast, changes to population-level genetic diversity (for example, expected heterozygosity) and genetic differentiation among subpopulations may require several generations to occur (Lowe et al., 2005). Theoretical models have shown that the loss of genetic diversity may proceed an order of magnitude more slowly than population differentiation (Varvio et al., 1986). Empirical studies have found that populations generally do not show declines in genetic diversity if few generations have passed, except in the most heavily fragmented landscapes (Lowe et al., 2005; Aguilar et al., 2008; Kramer et al. 2008, Vranckx et al., 2012).

${ }^{1}$ Department of Ecology and Evolutionary Biology, Tulane University, New Orleans, LA, USA and ${ }^{2}$ Department of Parks and Wildlife, Kensington, Western Australia, Australia Correspondence: Dr J Karubian, Department of Ecology and Evolutionary Biology, Tulane University, 400 Lindy Boggs Center, Saint Charles Avenue, New Orleans, LA, USA. E-mail: jk@tulane.edu

Received 28 May 2014; revised 20 March 2015; accepted 23 March 2015; published online 29 April 2015 
Extensive gene dispersal via pollen dispersal, seed dispersal or both may prevent genetic drift from eroding genetic diversity and increasing genetic differentiation among fragmented populations (Young et al., 1996; Sork et al., 1999; Hamrick, 2010). Effective dispersal may explain the resilience of certain plant species to the negative genetic consequences of habitat loss and fragmentation (Dick, 2001; White et al., 2002; Lowe et al., 2005; Noreen and Webb, 2013). For some species, gene flow may be enhanced in fragmented landscapes as dispersers are forced to move longer distances between plants or habitat patches (Dick, 2001; White et al., 2002). Pollen movement distances over $1 \mathrm{~km}$ have been recorded in several studies, and rates of gene flow into fragments or to isolated trees are higher in some cases than in continuous forest (see review in Hamrick, 2010). Less is known about the scale and diversity of seed-mediated gene flow in fragmented landscapes (Sork and Smouse, 2006; Hamrick, 2010), though seed movement appears to be sufficient for exchanging individuals between habitat patches in disturbed landscapes in at least some cases (Sezen et al., 2007).

We examined how habitat loss and fragmentation in northwest Ecuador impacts populations of Oenocarpus bataua, a large-seeded, outcrossing, animal-dispersed palm tree (Henderson et al., 1995). In doing so, our goal was to advance our understanding of how genetic characteristics of plant populations respond to recent habitat loss and fragmentation. Our study design was to compare genetic characteristics of $O$. bataua adults and recruits in a large continuous forest 'control' site with equivalent data from six forest fragments that have been isolated for $<2$ generations (30-40 years). Our working hypothesis was that allelic richness, genetic differentiation and finescale SGS would respond most strongly to this relatively recent fragmentation, whereas within-population gene diversity would not be impacted. We also hypothesized that inbreeding of $O$. bataua would not be affected due to its primarily outcrossing mating system (Ottewell et al., 2012).

\section{MATERIALS AND METHODS}

\section{Study species and sites}

O. bataua is a monecious canopy palm tree broadly distributed throughout the Neotropics (Henderson et al., 1995). It produces large inflorescences of thousands of small flowers; the most common pollinators are beetles (Curculionidae) and bees (Meliponinae; Nunez-Avellaneda and Rojas-Robles, 2008). Within continuous forest, pollen movement is extensive (mean effective pollination neighborhood $=18.5 \mathrm{ha}$ ) and self-fertilization is extremely rare (Ottewell et al., 2012). Ripe fruits are available for 4-8 weeks and present a large seed $(39.7 \pm 3.4 \mathrm{~mm}$ length $\times 22.7 \pm 2.2 \mathrm{~mm}$ width, mean \pm s.d., $n=394)$ surrounded by a thin, lipid-rich aril that is dispersed by large-bodied birds and mammals. In our study area, the long-wattled umbrellabird (Cephalopterus penduliger) is the most important primary seed-dispersal agent, removing more than half of the fruits (J Karubian, unpublished data), transporting seeds long distances (maximum recorded distance $=1338 \mathrm{~m}$, Karubian et al., 2012), and generating patches of dispersed seeds representing highly heterogeneous mixtures of maternal source trees (Karubian et al., 2010). Toucans (Ramphastos spp.) and squirrels (Sciurius spp.) also remove and disperse fruits directly from the tree (J Karubian, unpublished data). The Central American agouti (Dasyprocta punctata), lowland paca (Cuniculus paca), terrestrial birds and smaller rodents remove fallen fruits beneath fruiting trees and provide occasional secondary dispersal (L Browne and J Karubian, unpublished data). Insects in the families Scolytidae (bark beetles) and Blastobasidae (moths) are the most common seed predators (A. Franzke, unpublished data).

Data and samples were collected from Bilsa Biological Station (BBS; $79^{\circ} 45^{\prime} \mathrm{W}$, $0^{\circ} 22^{\prime} \mathrm{N}$; 330-730 m elevation) and six forest fragments (Table 1) within and surrounding the 120000 ha Mache-Chindul Ecological Reserve, Esmeraldas province, northwest Ecuador (Figure 1). The Mache-Chindul Ecological Reserve consists of humid Chocó rainforest (see Carrasco et al., 2013 for a
Table 1 Characteristics of study locations

\begin{tabular}{llrrr}
\hline Abbreviation & Name & $\begin{array}{c}\text { Area } \\
\text { (ha) }\end{array}$ & $\begin{array}{c}\text { Area sampled } \\
\text { (ha) }\end{array}$ & $\begin{array}{c}\text { Distance from } \\
\text { BBS (km) }\end{array}$ \\
\hline BBS & Bilsa Biological Station & 3500.0 & 130.0 & 0.0 \\
F1 & Taguales 1 & 42.5 & 16.5 & 2.6 \\
F2 & Taguales 2 & 36.3 & 16.1 & 2.4 \\
F3 & Descanso & 47.9 & 12.5 & 3.2 \\
F14 & Viche & 11.8 & 7.6 & 3.6 \\
F15 & Limón & 2.7 & 2.2 & 9.2 \\
F16 & Quinindé & $30.0^{\mathrm{a}}$ & 1.1 & 23.8 \\
\hline
\end{tabular}

Abbreviation, name, area, area sampled, distance from Bilsa Biological Station (BBS) for BBS and six forest fragments.

aEstimated.

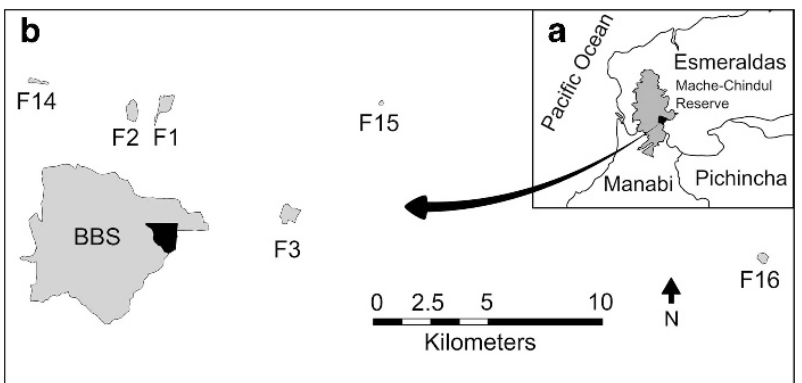

Figure 1 Map of study area showing location of (a) Mache-Chindul Reserve shaded gray and Bilsa Biological Station (BBS) shaded black in Esmeraldas and Manabí provinces, Ecuador; (b) BBS shaded gray, 130 ha study plot within BBS shaded black, and the six forest fragments sampled in this study. Area (ha) of each location and distance from BBS are provided in Table 1. Map only shows fragments sampled in this study, not all fragments actually present the study area (see Materials and methods 'Study species and sites').

full description). Most of the deforestation in Mache-Chindul Ecological Reserve has occurred in the past 30-40 years (Dodson and Gentry, 1993) and BBS remains the largest continous forest in the region (3500 ha). Habitat structure of BBS and fragments was qualitatively similar, with both presenting low levels of disturbance. We sampled 142 points in BBS and 113 points across all fragments and found that differences in the average canopy height (mean \pm s.e.: $21.4 \pm 0.6 \mathrm{~m}$ in BBS vs $22.2 \pm 0.6 \mathrm{~m}$ in fragments) and percent canopy cover $(94.7 \pm 0.2 \%$ vs $93.3 \pm 0.2 \%)$ were minimal. Within BBS, we worked within an established 130 ha study plot where all adult O. bataua $(n=185)$ have been mapped and genotyped (see Ottewell et al., 2012). We identified fragments located on private land surrounding BBS within a matrix dominated by pasture, where $O$. bataua is occasionally left as a remnant tree. The area of each fragment was obtained by walking fragment borders with a hand-held GPS (Garmin, Kansas City, MO, USA) because adequate remote-sensing imagery is not currently available for the region (see below).

\section{Genetic sampling}

To evaluate genetic diversity and structure in BBS and fragments, we sampled different components of the O. bataua recruitment cycle: adults (individuals with evidence of reproduction such as active or old inflorescences) and recruits (0.25-1.5 $\mathrm{m}$ in height). O. bataua seeds remain attached to the base of seedlings for $<2$ years after germination (J Karubian, unpublished data). Each recruit sampled had a seed attached to its base, placing all recruits within a similar age class that clearly established post fragmentation. The average height of adults in BBS $(20.6 \mathrm{~m} \pm 0.4$, mean \pm s.e.) was lower than adults pooled across fragments $(22.5 \mathrm{~m} \pm 0.5)$, though there was variation in the average heights between fragments (Supplementary Table S1). On the basis of nearly a decade of 
measuring growth rates of $O$. bataua in BBS, we estimate adults in this study to be at least 30 years of age (J Karubian, unpublished data), meaning that the large majority of adults in both BBS and study fragments are likely to have established before fragment formation.

We divided recruits into 'beneath recruits' (found beneath the canopy of an adult $O$. bataua) and 'dispersed recruits' (found at least $10 \mathrm{~m}$ away from the nearest adult $O$. bataua). We chose this arbitrary distance of $10 \mathrm{~m}$ because it is very unlikely that a seed would move this distance from the tree without assistance from an animal dispersal vector (see also Choo et al., 2012). Adults in BBS were located within the 130 ha study plot (above); adults in fragments were sampled opportunistically. For beneath recruits, we sampled multiple individuals from groups of recruits located underneath adult trees. Dispersed recruits were located opportunistically by searching $>10 \mathrm{~m}$ from adults for established recruits. The majority of dispersed recruits were collected as singletons, but when a group of dispersed recruits was encountered (in an area $<2 \mathrm{~m}^{2}$ ), we sampled multiple individuals from that location. The total number of sampling locations was higher in BBS $(n=202)$ than fragments $(n=77)$, though the average number of individuals per location were similar between BBS (1.5 individuals per location) and fragments (1.6 individuals per location, Supplementary Table S1). Pairwise and nearest-neighbor distances between sampled individuals were also similar, apart from F15 and F16, which had the smallest sampled area (Table 1) and lower pairwise and nearest-neighbor distances (Supplementary Figure S1,Supplementary Table S1). The location of each individual sampled was recorded using a GPS $( \pm 7 \mathrm{~m}$ accuracy; Garmin, Kansas City, MO, USA).

We genotyped a total of $890 \mathrm{O}$. bataua individuals ( 300 adults, 172 beneath recruits, 418 dispersed recruits; Table 2). Leaf tissue from recruits and tissue from the roots, leaves or surface of the trunk from adults were collected between 2007 and 2010 and stored in dry conditions until DNA extraction. DNA was extracted and PCR amplified at 11 microsatellite loci following Ottewell et al. (2012); one locus, Ob04, did not amplify for a subset of samples and thus was excluded from analyses, resulting in a suite of 10 loci. The genotyping error rate (calculated by re-amplifying and re-genotypying $~ 5 \%$ of the samples) was $2.05 \%$ (Supplementary Table S2). We tested for linkage disequilibrium and departure from Hardy-Weinberg equilibrium within sites and sample classes using default parameters (dememorization $=10000$, batches $=20$, iterations per batch $=5000$ ) in Genepop v. 4.2 (Raymond and Rousset, 1995; Supplementary Appendix S1). Genotype data were checked for scoring errors and the presence and frequency of null alleles using MicroChecker v. 2.2.3 (iterations $=10000$; Van Oosterhout et al., 2004; Supplementary Appendix S1)

\section{Genetic diversity, inbreeding and genetic differentiation}

To quantify genetic diversity and inbreeding, we calculated allelic richness $(A)$, rarefied allelic richness $\left(A_{\mathrm{r}}\right.$, rarefied to $n=16$ samples), observed heterozygosity $\left(H_{\mathrm{o}}\right)$, within-population gene diversity $\left(H_{\mathrm{s}} ; \mathrm{Nei}, 1987\right)$ and the inbreeding coefficient $\left(F_{\text {is }}\right)$ using the package 'hierfstat' in R v. 2.15 .2 (Goudet, 2005; R Development Core Team, 2012). We used $A_{\mathrm{r}}, H_{\mathrm{o}}, H_{\mathrm{s}}, F_{\text {is }}$ to compare genetic diversity and inbreeding of adults, beneath recruits and dispersed recruits between fragments and BBS. Unless mentioned otherwise, we pooled adults, beneath recruits and dispersed recruits across fragments; all analyses were also re-run with individuals grouped by fragment (Supplementary Table S3). To test for differences in genetic diversity and inbreeding of adults, beneath recruits and dispersed recruits between fragments and BBS, we used a randomized blocked analysis of variance with loci as the blocking factor after arcsine square root transforming $H_{\mathrm{o}}$ and $H_{\mathrm{s}}$. We conducted post hoc comparisons using the Tukey Honest Significant Differences test. For each analysis of variance, we confirmed that model assumptions were met (for example, normality of residuals, homogeneity of variance). These analyses were performed in R v. 2.15.2 (R Development Core Team, 2012).

We evaluated inter-population genetic differentiation of $O$. bataua with Jost's estimator of differentiation $D_{\text {est }}$ (Jost, 2008). We also present $F_{\text {st }}$ results to allow comparison with past studies, though $F_{\text {st }}$ is limited in estimating genetic differentiation with highly polymorphic markers, such as the ones used in this study (Jost, 2008). We conducted pairwise comparisons of all the locations for adults, beneath recruits and dispersed recruits separately. $D_{\text {est }}$ and $F_{\text {st }}$ were calculated and significance was tested via permutation of individuals among locations $(n=999)$ in GenAlEx 6.5 (Peakall and Smouse, 2012). A hierarchical analysis of molecular variance was used to analyze the distribution of genetic variation among and within locations (BBS and fragments) for each of adults, beneath recruits and dispersed recruits in Arlequin (Excoffier and Lischer, 2010). We tested the null hypothesis that there would be no division of genetic variation between locations using permutation of individuals among locations $(n=1000)$.

\section{Fine-scale spatial genetic structure}

To assess the strength of intra-population fine-scale SGS, we performed spatial autocorrelation analysis using the kinship coefficient $F_{i j}$ of Loiselle et al. (1995) in the program SPAGeDi v. 1.4 (Hardy and Vekemans, 2002). Following the recommendations of Hardy and Vekemans (2002), we chose distance intervals such that each interval had a minimum of 100 pairwise comparisons, included $>50 \%$ of individuals and had a coefficient of variation of participation $<1.0$ (Supplementary Table S4). Because the sampling size and scale varied between locations, the overall number of intervals varied between 5 and 8 (Supplementary Table S4). Adults, beneath recruits and dispersed recruits were pooled across fragments, though analyses were also conducted at the individual fragment level (Supplementary Table S4). For analyses pooled across fragments, reference allele frequencies used in the estimation of $F_{i j}$ were calculated separately for each fragment. For the analyses of individuals pooled across fragments vs BBS, we used equivalent distance intervals to aid in direct comparison.

The overall strength of SGS was calculated using the $S p$ statistic of Vekemans and Hardy (2004). The $S p$ statistic is calculated as $-b_{\mathrm{Flog}} /\left(1-F_{1}\right)$, where $b_{\mathrm{Flog}}$ is the mean slope of the regression of kinship coefficient of Loiselle et al. (1995) on a $\log _{10}$ distance scale, and $F_{1}$ is the mean kinship coefficient of the first distance class. The $S p$ statistic is robust to the choice of distance intervals (Vekemans and Hardy, 2004), but to ensure that our results were not dependent on the arbitrary choice of distance intervals, we recalculated $S p$ for adults, beneath recruits and dispersed recruits pooled across fragments and in BBS with the number of distance intervals ranging from 2 to 16 and found that indeed our estimates of $S p$ were robust to the number of chosen distance

Table 2 Genetic estimators

\begin{tabular}{llccrrr}
\hline Type & Location & $\mathrm{N}$ & $\mathrm{A}_{r}$ & $\mathrm{H}_{0}$ & $\mathrm{H}_{s}$ \\
\hline Adult & BBS & 185 & $5.51( \pm 0.66)$ & $0.68( \pm 0.06)$ & $0.67( \pm 0.05)$ & $-0.01( \pm 0.02)$ \\
& Fragments pooled & 115 & $5.61( \pm 0.74)$ & $0.67( \pm 0.04)$ & $0.69( \pm 0.05)$ & $0.02( \pm 0.02)$ \\
Beneath & BBS & 52 & $5.28( \pm 0.55)$ & $0.67( \pm 0.06)$ & $0.66( \pm 0.05)$ & $-0.02( \pm 0.03)$ \\
& Fragments pooled & 120 & $5.51( \pm 0.62)$ & $0.63( \pm 0.05)$ & $0.66( \pm 0.05)$ & $0.04( \pm 0.01)$ \\
Dispersed & BBS & 296 & $5.56( \pm 0.61)$ & $0.57( \pm 0.05)$ & $0.65( \pm 0.06)$ & $0.11( \pm 0.02)$ \\
& Fragments pooled & 122 & $5.71( \pm 0.63)$ & $0.62( \pm 0.04)$ & $0.68( \pm 0.05)$ & $0.07( \pm 0.02)$
\end{tabular}

Genetic estimators of Oenocarpus bataua for adults, beneath recruits and dispersed recruits at Bilsa Biological Station (BBS) and pooled across six forest fragments; sample size ( $N$ ), rarefied allelic richness $\left(A_{\mathrm{r}}\right)$ to $n=16$ samples, observed heterozygosity $\left(H_{0}\right)$, within-population gene diversity $\left(H_{\mathrm{s}}\right)$, inbreeding coefficient $\left(F_{\text {is }}\right)$. Standard errors $(\mathrm{s}$.e. $)$ are given in parentheses. 
intervals and size of the first distance class (Supplementary Table S5). To assess whether differences in area sampled (Table 1) affected the SGS analyses, we re-did analyses restricting the maximum distance used in estimating $b_{\text {Flog }}$ to the lowest maximum pairwise difference for each collection type (adults $=103 \mathrm{~m}$, beneath recruits $=48 \mathrm{~m}$, dispersed recruits $=68 \mathrm{~m}$ ). These results did not differ substantively from $b_{\text {Flog }}$ estimates using the full distance range, and thus we only present those results. To test whether SGS differed between BBS and fragments, we conducted a randomized blocked analysis of variance using loci as the blocking factor on the per-locus estimates of $S p$. These analyses were performed in R v. 2.15.2 (R Development Core Team, 2012).

\section{RESULTS}

\section{Genetic diversity, inbreeding and differentiation}

We found no significant differences in measures of genetic diversity $\left(A_{\mathrm{r}}, H_{\mathrm{o}}, H_{\mathrm{s}}\right)$ between adults, beneath recruits and dispersed recruits in BBS and fragments (pooled, Table 2). When analyzed individually, only one fragment (F15) showed consistently lower measures of allelic richness $\left(A_{\mathrm{r}}\right)$ and within-population gene diversity $\left(H_{\mathrm{s}}\right)$ than in BBS for both adults and recruits (Supplementary Table S3). There was no significant difference in the inbreeding coefficient $\left(F_{\text {is }}\right)$ between BBS and fragments (pooled) for either adults or recruits (Table 2).

We found significant genetic differentiation among locations (BBS and individual fragments) for adults, beneath recruits and dispersed recruits. The overall strength of differentiation, which includes comparisons of BBS to fragments as well as pairwise comparisons among fragments, was highest in dispersed recruits $\left(D_{\text {est }}=0.107 \pm\right.$ 0.020 (s.e.), $\left.F_{s t}=0.047 \pm 0.006\right)$, followed by beneath recruits $\left(D_{e s t}=\right.$ $\left.0.067 \pm 0.019, F_{s t}=0.031 \pm 0.005\right)$, then adults $\left(D_{\text {est }}=0.042 \pm 0.018\right.$, $\left.F_{s t}=0.017 \pm 0.006\right)$ (Supplementary Table S6). Pairwise $D_{\text {est }}$ between just BBS and the six fragments was again highest in dispersed recruits $(0.079 \pm 0.012)$, followed by beneath recruits $(0.059 \pm 0.009)$, then adults $(0.035 \pm 0.010)$ (Supplementary Table S6). For both dispersed and beneath recruits, differences among populations $(4.32 \%$ and $3.45 \%$, respectively) explained approximately twice as much variation as it did for adults $(1.76 \%, P<0.001$, analysis of molecular variance).

\section{Fine-scale spatial genetic structure}

Significant fine-scale SGS was found for adults, beneath recruits, and dispersed recruits in BBS, and for beneath and dispersed recruits pooled across fragments (Table 3). Adults pooled across fragments did not show significant SGS (Table 3). The strength of SGS was higher for dispersed recruits in fragments $(S p=0.0194)$ than for dispersed recruits in BBS $(S p=0.0035)(\mathrm{F}=19.9, \mathrm{df}=1, P=0.002)$, as well as for beneath recruits in fragments $(S p=0.0190)$ vs beneath recruits in BBS $(S p=0.0113$; Table 3, F $=5.24, \mathrm{df}=1, P=0.04)$. The strength of SGS did not differ between adults in fragments and adults in BBS $(\mathrm{F}=0.035, \mathrm{df}=1, P=0.856)$. When this analysis was repeated excluding one fragment with particularly high SGS (F16;
Supplementary Table S4), dispersed recruits continued to show significantly higher $S p$ in fragments than in BBS (0.0115 vs 0.0034 , respectively; $\mathrm{F}=8.3, \mathrm{df}=1, P=0.0183$ ); among beneath recruits, the difference was no longer statistically significant $(0.177$ in fragments vs 0.113 in BBS; $\mathrm{F}=2.3$, $\mathrm{df}=1, P=0.163$ ).

\section{DISCUSSION}

Understanding how habitat loss and fragmentation impact animaldispersed plants depends in large part on identifying how genetic characteristics of populations will respond to these forms of disturbance. To address this question, we compared cohorts of the animaldispersed palm Oenocarpus bataua in continuous forest (BBS) and six forest fragments in a recently fragmented landscape $(<2$ generations, 30-40 years). We found no differences in genetic diversity between fragmented and continuous populations, but we did observe stronger fine-scale SGS among recruits in forest fragments compared with their counterparts in continuous forest. We also found that genetic differentiation among populations was higher for recruits than for adults, both when comparing across all populations and when comparing BBS directly with fragmented populations. There was no difference in inbreeding in BBS and fragments for recruits or adults, congruent with our prediction on the basis of similar findings from an earlier study (Ottewell et al., 2012). These results suggest that, in the short term, genetic diversity can be maintained in fragmented landscapes among early generations of this long-lived palm species, despite increasing levels of within- and between-population genetic structure among recruits. However, we do note that the evidence of increasing genetic differentiation and structure detected may be early warning signals for an anthropogenic impact on the evolutionary trajectory for O. bataua in our study area.

Genetic diversity of recruits in fragmented and continuous forest was equivalent, congruent with the expectation that genetic diversity will not respond immediately to habitat loss and fragmentation, unless remnant populations are very small and isolated (Young et al., 1996; Lowe et al., 2005; Kramer et al., 2008; Vranckx et al., 2012). Surprisingly, we found comparable levels of allelic richness, despite it being a particularly sensitive parameter to habitat loss and fragmentation (Lowe et al., 2005). One possible explanation is that the genetic bottleneck following deforestation was not severe enough to lower the effective size of remnant populations to a point where loss of genetic diversity would be pronounced (Young et al., 1996; Lowe et al., 2005; Kramer et al., 2008). This could lead to high standing genetic diversity in adults left after fragmentation, providing a buffer against genetic erosion (Hamrick, 2004). Only adults and dispersed recruits in the smallest fragment in this study (F15, 2.7 ha) showed lower within-population gene diversity and allelic richness than their

Table 3 Summary of fine-scale spatial genetic structure analysis

\begin{tabular}{|c|c|c|c|c|c|}
\hline Type & Location & $\mathrm{D}_{1}$ & $\mathrm{~F}_{\mathrm{ij} 1}$ & $\mathrm{~b}_{\text {Flog }}$ & $\mathrm{Sp}$ \\
\hline \multirow[t]{2}{*}{ Adult } & BBS & 28 & $0.0111( \pm 0.0086)$ & $-0.0025( \pm 0.0009)$ & 0.0025 \\
\hline & Fragments pooled & 28 & $0.009( \pm 0.0071)$ & $\overline{-0.0034( \pm 0.0046)}$ & 0.0034 \\
\hline Beneath & Fragments pooled & 6 & $0.0794( \pm 0.0072)$ & $\overline{-0.0175( \pm 0.0016)}$ & $\underline{0.0190^{*}}$ \\
\hline \multirow[t]{2}{*}{ Dispersed } & BBS & 10 & $0.0202( \pm 0.0037)$ & $-0.0034( \pm 0.0005)$ & $\overline{0.0035}$ \\
\hline & Fragments pooled & 10 & $\overline{0.0772( \pm 0.0096)}$ & $\overline{-0.0179( \pm 0.0024)}$ & $0.0194^{*}$ \\
\hline
\end{tabular}

Summary of fine-scale spatial genetic structure (SGS) analysis of Oenocarpus bataua adults, beneath recruits and dispersed recruits at Bilsa Biological Station (BBS) and pooled across six forest fragments. Maximum distance in first distance interval $\left(D_{1}\right)$, kinship coefficient in first distance interval $\left(F_{i j 1}\right)$, slope of the regression of the kinship coefficient on spatial distance $\left(b_{\text {Flog }}\right)$, and strength of SGS $(S p)$. Standard errors (s.e.) are given in parentheses. Underlined $F_{i j 1}$ and $b_{\text {Flog }}$ indicate significant values $(P<0.05 ; 10000$ permutations of individuals among locations). Bold and asterisked $S p$ values indicate that the strength of SGS in samples pooled across fragments differed significantly from BBS $(P<0.05)$. 
counterparts in BBS, though it remains unclear whether this is a result of a genetic bottleneck and/or altered gene flow.

Alternatively, a loss of genetic diversity could be mitigated if between-fragment gene flow via pollen or seeds or both is maintained or even enhanced following fragmentation (Sork et al., 1999; Hamrick, 2010). However, if gene flow between fragments were maintained or increased, one would also predict that genetic differentiation would remain stable or possibly decrease (Hamrick, 2010). We detected an increase in genetic differentiation among recruits post fragmentation, suggesting altered patterns of gene flow, but it is difficult to reach any firm conclusions about whether gene flow is increasing or decreasing within the limitations of this current study. For example, it is possible that genetic diversity is maintained in our system through gene flow between sampled and nearby unsampled fragments or remnant trees, which may represent more or less isolated/discrete breeding neighborhoods due to restrictions to foraging distances or other barriers to gene flow, which can then generate greater differentiation among recruits in sampled fragments. Alternatively, if gene flow across the landscape were limited, we would also expect to see an increase in differentiation among populations, but also a corresponding loss of genetic diversity (Young et al., 1996; Hamrick, 2010). Genetic differentiation might increase without a corresponding loss to diversity if parental densities were reduced to a level that would cause local differentiation in allele frequencies through a random sampling effect without an overall loss of genetic diversity. The fact that the density of adults for most fragments sampled in this study were higher than in BBS makes this unlikely in this system (Supplementary Table S8). Notably, we found low but significant genetic differentiation among adults that were presumably established before fragmentation, which suggests that genetic variation may have been nonrandomly distributed across the landscape before fragmentation due to natural barriers/ limits to gene flow, which may interact with any fragmentation effects (Hamrick, 2010). A direct analysis of gene flow (for example, parentage analysis) that quantifies the number of migration events among fragments, along with a better understanding of natural barriers to gene flow in continuous landscapes would be useful to identify the drivers of genetic differentiation in this system.

It is also worth noting that the lack of a detectable response of genetic diversity to fragmentation may be owing to the fact that not enough generations have passed for an effect to be noticeable (Kramer et al., 2008). We estimate that the 30-40 years since fragmentation in this landscape corresponds to at the most two generations of O. bataua. In a meta-analysis of genetic consequences of fragmentation on plant populations, Aguilar et al. (2008) found that there was a small but nonsignificant decrease in heterozygosity $\left(H_{\mathrm{e}}\right)$ and allelic richness for populations experiencing $<50$ years of fragmentation, whereas the decrease was larger and statistically significant for populations experiencing at least 100 years of fragmentation. Similarly, in a separate meta-analysis, plants experiencing $<1$ generation since fragmentation was shown to have, on average, no significant decline in genetic diversity, while those experiencing $>1$ generation showed large and significant declines (Vranckx et al., 2012).

Patterns of fine-scale SGS arise from a complex interaction of factors, including but not limited to the magnitude of pollen and seed dispersal, the pollen and seed pool structure, and population density (Vekemans and Hardy, 2004). Fine-scale SGS also commonly changes throughout the life cycle of plants, generally strongest at early-life stages and declining over time (Hamrick et al., 1993; Choo et al., 2012). We recovered a similar pattern in which young recruits had stronger fine-scale SGS than adults in all comparisons, but more interestingly, recruits in fragments had significantly stronger fine-scale
SGS than did their counterparts in continuous forest. All the recruits were sampled at $<2$ years of age so it is unlikely that age differences between fragments and BBS could be driving this pattern. Lower plant densities can also explain stronger fine-scale SGS (Hamrick et al., 1993; Vekemans and Hardy, 2004). In our system, most fragments (four of six) had higher estimated adult densities than did BBS (Supplementary Table S8), along with higher SGS, including F16, which had the highest fine-scale SGS in dispersed recruits. Interestingly, however, the density of both beneath and dispersed recruits was generally lower in fragments than in BBS (Supplementary Table S8), which may provide a partial explanation of the increase in fine-scale SGS in fragments (the mechanisms behind the reduced density of recruits in fragments relative to BBS remain unclear).

The difference in SGS between fragments and BBS was greater for dispersed recruits than for beneath recruits (Figure 2), suggesting that pollen- and seed-mediated gene flow are differentially affected by habitat loss and fragmentation in this system. If pollen dispersal were impacted by fragmentation, we would expect to see a strong effect on SGS in beneath seedlings in fragments compared with BBS, assuming that beneath recruits in both fragments and BBS experience very limited seed dispersal (that is, falling from the infructescence to beneath the adult canopy), and the resulting genetic structure contributed by this limited level of seed dispersal would be similar in both forest types. Alternatively, if seed dispersal were strongly

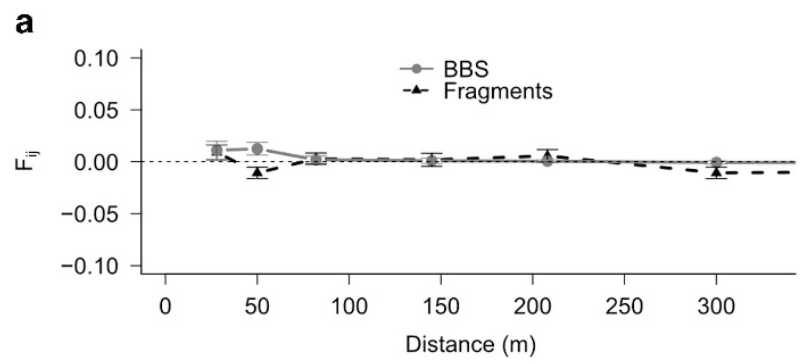

b

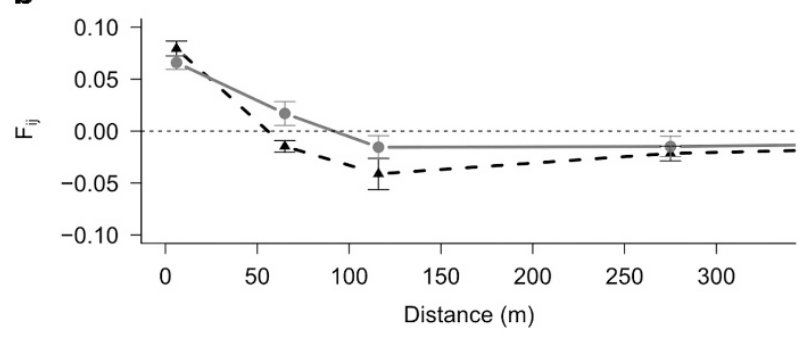

C

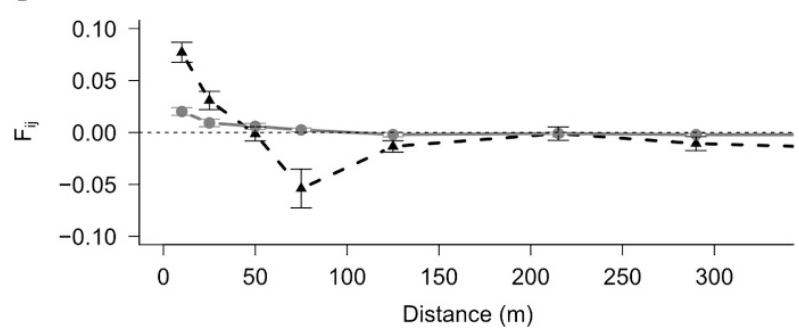

Figure 2 Spatial autocorrelation analysis of Oenocarpus bataua for (a) adults, (b) beneath recruits and (c) dispersed recruits in Bilsa Biological Station (BBS, solid gray line with circle) and fragments (dashed black line with triangle). Relationship coefficient $\left(F_{i j}\right)$ plotted against distance. Error bars are \pm 1 s.e. estimated by jackknifing across loci. The maximum distance was truncated at $350 \mathrm{~m}$ to improve clarity. 
impacted by fragmentation, we would expect to see a strong difference between fragments and continuous forest in SGS for dispersed recruits, but not necessarily for beneath recruits, because the SGS of dispersed recruits is likely strongly influenced by seed-dispersal processes (Wang et al., 2011). A change in the SGS of recruits could arise from a combination of a restriction of dispersal distance of either pollen or seed (Vekemans and Hardy, 2004) or a change to the pollen and seed pool structure that would result in higher levels of relatedness among dispersed individuals or both. The larger differences in SGS in dispersed recruits between BBS and fragments suggest greater impacts of habitat loss and fragmentation on seed-dispersal processes than pollen dispersal. However, we suggest caution when interpreting these results as we provide only indirect evidence of this effect, the mechanisms at play remain unclear and we cannot rule out other potential contributing factors like differences in the densities of recruits.

Lack of replication is a pervasive problem in fragmentation studies (Lowe et al., 2005). In this study, we compared six fragments to one continuous forest, without replication among continuous forest sites or among landscapes, and careful consideration must be made before extrapolating the conclusions of this study beyond the sampled populations. It is also worth noting that, due to a lack of cloud-free remote-sensing images, we were not able to obtain a land-cover map of the study area, and thus were unable to characterize the matrix between fragments and map the boundaries of all fragments in the region. Consequently, we were not able assess how fragment isolation and matrix relate to the results of this study, though they are known to be important in other systems (Prugh et al., 2008). Finally, we were not able to distinguish between the separate processes of habitat loss and habitat fragmentation (Fahrig, 2003), although, in our study area, these phenomena typically occur in tandem and thus it is their combined effects that pose a potential threat to the evolutionary potential of $O$. bataua.

In summary, we provide evidence of differential short-term responses of genetic characteristics to a recent fragmentation event: fine-scale SGS and genetic differentiation responded strongly, whereas genetic diversity and inbreeding did not show a strong response. Finescale SGS, in particular, appears to be a sensitive and useful tool for detecting genetic changes following habitat loss and fragmentation, though additional study is needed to discern causative mechanisms. Many tropical tree species rely on animals for dispersal of pollen and seed (Herrera, 2002; Ollerton et al., 2011), and understanding how the integrity of these mutualistic interactions is maintained in degraded landscapes is a priority. Directly measuring the relative importance of gene flow via pollen vs seed dispersal, identifying how landscape characteristics and matrix quality influence gene flow and conducting comparative longitudinal analyses are priorities for future work on this system.

\section{DATA ARCHIVING}

Data have been submitted to Dryad: http://dx.doi.org/10.5061/ dryad.v025v.

\section{CONFLICT OF INTEREST}

The authors declare no conflict of interest.

\section{ACKNOWLEDGEMENTS}

Valuable assistance in the field and/or lab was provided by C Anton, D Cabrera J Cabrera, F Castillo, M Newman and J Olivo. We are grateful to the staff of the Jatún Sacha Foundation and Bilsa Biological Station, particularly C Aulestia, J Bermingham and S Sandoval, and to Fundación Conservación de los Andes Tropicales, especially M. Gonzalez, as well as previous reviewers whose comments greatly improved the quality of the manuscript. We thank the local residents of the Mache-Chindul Reserve for conserving remaining forest fragments in the area and supporting our research. This project was supported by the Disney Worldwide Conservation Fund, Louisiana Board of Regents, National Geographic Society, National Science Foundation and Tulane University. All research was conducted with approval of the Ecuadorian Ministry of the Environment (Permit 009- CI-FAU- DRE-MA).

Aguilar R, Quesada M, Ashworth L, Herrerias-Diego Y, Lobo J (2008). Genetic consequences of habitat fragmentation in plant populations: susceptible signals in plant traits and methodological approaches. Mol Ecol 17: 5177-5188.

Breed MF, Marklund MHK, Ottewell KM, Gardner MG, Harris JBC, Lowe AJ (2012). Pollen diversity matters: revealing the neglected effect of pollen diversity on fitness in fragmented landscapes. Mol Ecol 21: 5955-5968.

Carrasco L, Berg K, Litz J, Cook A, Karubian J (2013). Avifauna of the Mache Chindul Ecological Reserve, Northwest Ecuador. Ornitol Neotrop 24: 321-334.

Choo J, Juenger TE, Simpson BB (2012). Consequences of frugivore-mediated seed dispersal for the spatial and genetic structures of a neotropical palm. Mol Ecol 21: 1019-1031.

Dick CW (2001). Genetic rescue of remnant tropical trees by an alien pollinator. Proc $R$ Soc London Ser B Biol Sci 268: 2391-2396.

Dodson C, Gentry A (1993). Extinción biológica en el Ecuador occidental. In: Mena P, Suárez L (eds) La investigación para la conservación de la diversidad biológica en el Ecuador. EcoCiencia: Quito, Ecuador.

Excoffier L, Lischer HEL (2010). Arlequin suite ver 3.5: a new series of programs to perform population genetics analyses under Linux and Windows. Mol Ecol Resour 10 564-567.

Fahrig L (2003). Effects of habitat fragmentation on biodiversity. Annu Rev Ecol Evol Syst 34: 487-515.

Goudet J (2005). HIERFSTAT, a package for $\mathrm{R}$ to compute and test hierarchical F-statistics. Mol Ecol Notes 5: 184-186.

Hamrick J (2004). Response of forest trees to global environmental changes. For Ecol Manage 197: 323-335.

Hamrick J (2010). Pollen and seed movement in disturbed tropical landscapes. In: DeWoody JA, Bickham JW, Michler CH, Nichols KM, Rhodes OE, Woeste KE (eds) Molecular Approaches in Natural Resource Conservation and Management. Cambridge University Press: New York, NY, USA. pp 190-211.

Hamrick J, Murawski D, Nason J (1993). The influence of seed dispersal mechanisms on the genetic structure of tropical tree populations. In: Fleming T, Estrada A (eds) Frugivory and seed dispersal: ecological and evolutionary aspects. Kluwer Academic Publishers: Belgium. pp 281-297.

Hardy O, Vekemans X (2002). SPAGeDi: a versatile computer program to analyse spatial genetic structure at the individual or population levels. Mol Ecol Notes 2: 618-620.

Henderson A, Galeano G, Bernal R (1995). Field Guide to the Palms of America. Princeton University Press: Princeton, NJ, USA.

Herrera CM (2002). Seed dispersal by vertebrates. In: Herrera CM, Pellmyr O (eds) Plant-animal interactions: an evolutionary approach. Blackwell Publishing: Oxford, UK pp 185-208.

Jost L (2008). Gst and its relatives do not measure differentiation. Mol Ecol 17 4015-4026

Karubian J, Durães R, Storey JL, Smith TB (2012). Mating behavior drives seed dispersal by the Long-wattled Umbrellabird Cephalopterus penduliger. Biotropica 44: 689-698.

Karubian J, Sork VL, Roorda T, Durães R, Smith TB (2010). Destination-based seed dispersal homogenizes genetic structure of a tropical palm. Mol Ecol 19: 1745-1753.

Kramer AT, Ison JL, Ashley M V, Howe HF (2008). The paradox of forest fragmentation genetics. Conserv Biol 22: 878-885.

Loiselle B, Sork V, Nason J, Graham C (1995). Spatial genetic structure of a tropical understory shrub, Psychotria officinalis (Rubiaceae). Am J Bot 1420-1425.

Lowe AJ, Boshier D, Ward M, Bacles CFE, Navarro C (2005). Genetic resource impacts of habitat loss and degradation; reconciling empirical evidence and predicted theory for neotropical trees. Heredity 95: 255-273.

Nei M (1987). Molecular Evolutionary Genetics. Columbia University Press: New York, NY, USA.

Noreen AME, Webb EL (2013). High genetic diversity in a potentially vulnerable tropica tree species despite extreme habitat loss. PLoS One 8: 1-10.

Nunez-Avellaneda L, Rojas-Robles R (2008). Reproductive biology and pollination ecology of the milpesos palm Oenocarpus bataua in the Colombian Andes. Caldasia 30: 101-125.

Ollerton J, Winfree R, Tarrant S (2011). How many flowering plants are pollinated by animals? Oikos 120: 321-326.

Van Oosterhout C, Hutchinson WF, Wills DPM, Shipley P (2004). Micro-Checker: Software for identifying and correcting genotyping errors in microsatellite data. Mol Ecol Notes 4 535-538.

Ottewell K, Grey E, Castillo F, Karubian J (2012). The pollen dispersal kernel and mating system of an insect-pollinated tropical palm, Oenocarpus bataua. Heredity 109 332-339.

Peakall R, Smouse PE (2012). GenALEx 6.5: Genetic analysis in Excel. Population genetic software for teaching and research-an update. Bioinformatics 28: 2537-2539. 
Prugh LR, Hodges KE, Sinclair ARE, Brashares JS (2008). Effect of habitat area and isolation on fragmented animal populations. Proc Natl Acad Sci USA 105: 20770-20775.

Raymond M, Rousset F (1995). GENEPOP (version 1.2): population genetics software for exact tests and ecumenicism. J Hered 86: 248-249.

R Development Core Team (2012). R: A Language and Environment for Statistical Computing. R Foundation for Statistical Computing: Vienna, Austria. Available at http://www.R-project.org/.

Sezen U, Chazdon R, Holsinger K (2007). Multigenerational genetic analysis of tropical secondary regeneration in a canopy palm. Ecology 88: 3065-3075.

Sork V, Nason J, Campbell D, Fernandez J (1999). Landscape approaches to historical and contemporary gene flow in plants. Trends Ecol Evol 14: 219-224.

Sork VL, Smouse PE (2006). Genetic analysis of landscape connectivity in tree populations. Landsc Ecol 21: 821-836.
Varvio S, Chakraborty R, Nei M (1986). Genetic variation in subdivided populations and conservation genetics. Heredity 57: 189-196.

Vekemans X, Hardy OJ (2004). New insights from fine-scale spatial genetic structure analyses in plant populations. Mol Ecol 13: 921-935.

Vranckx G, Jacquemyn H, Muys B, Honnay O (2012). Meta-analysis of susceptibility of woody plants to loss of genetic diversity through habitat fragmentation. Conserv Bio/ 26: 228-237.

Wang R, Compton SG, Chen X (2011). Fragmentation can increase spatial genetic structure without decreasing pollen-mediated gene flow in a wind-pollinated tree. $\mathrm{Mol} E \mathrm{EO} / 20$ : 4421-4432.

White GM, Boshier DH, Powell W (2002). Increased pollen flow counteracts fragmentation in a tropical dry forest: an example from Swietenia humilis Zuccarini. Proc Natl Acad Sci USA 99: 2038-2042.

Young A, Boyle T, Brown T (1996). The population genetic consequences of habitat fragmentation for plants. Trends Ecol Evol 11: 413-418.

Supplementary Information accompanies this paper on Heredity website (http://www.nature.com/hdy) 